\title{
INFORMÁTICA E SOCIEDADE NO ENSINO DE PROGRAMAÇÃO
}

\author{
Informatics and Society in Programming Courses
}

\author{
André Vinicius Leal Sobral ${ }^{*}$
}

Nayara Gomes da Silva**

\begin{abstract}
Resumo: Este trabalho visa apresentar os resultados, desafios e aprendizados do curso de introdução à programação em Python, Java e C++, oferecido pelos Laboratório de Informática para Educação (LIpE) e Laboratório de Informática e Sociedade (LabIS), ambos da Universidade Federal do Rio de Janeiro (UFRJ), para um público diversificado e majoritariamente oriundo do ensino médio de escolas públicas do estado. Iniciado nas escolas do Rio, devido à necessidade de estudantes capacitados e engajados na manutenção e operação de laboratórios de informática restaurados pelo LIpE e reforçado pelo voluntarismo de estudantes universitários, o curso conta com centenas de estudantes e mais de três anos de realização bem-sucedida. Sustentado por mão de obra voluntária e baseado em tutoria, combinamos o ensino teórico e prático da programação com aulas contextuais que discutem a história e implicações sociotécnicas da computação. Contamos também com turmas dedicadas a mulheres, com monitoras e professoras para incentivar a maior participação feminina na área da tecnologia e computação. Vários estudantes egressos do curso conseguiram melhorar seu desempenho escolar a ponto de passar no vestibular para a UFRJ e tornam-se colaboradores voluntários como monitores para a continuidade do projeto. O curso é exemplo da integração do tripé acadêmico ensino-pesquisa-extensão, integrando as pesquisas produzidas pela linha de pesquisa em Informática e Sociedade do Programa de Pós-Graduação em Engenharia de Sistemas e Computação (PESC) da UFRJ nas aulas contextuais e servindo como laboratório para o desenvolvimento de materiais didáticos e softwares.
\end{abstract}

Palavras-chave: Informática. Sociedade. Programação.

\begin{abstract}
This essay aims to present the results and challenges faced by the programing course in Python, Java and C++ offered by the Laboratory of Informatics for Education (LIpE) in partnership with the Informatics and Society Laboratory (LabIS), both in Federal University of Rio de Janeiro (UFRJ). Designed for a socially diversified public from public high school of Rio, this course has been born from the maintenance necessity of the informatics laboratories that were restored by LIPE. Through the efforts of voluntary undergrad students, it has been possible to maintain this programming course by more than three years, aiding more than three hundred students since its beginnings. A combination of theoretical and practical

\footnotetext{
* Sociólogo formado pela Universidade Federal da Bahia (2013), Mestre em Engenharia de Sistemas e Computação na linha de pesquisa em Informática e Sociedade pela Universidade Federal do Rio de Janeiro (2016) e atualmente doutorando na mesma área e instituição. lealsobral@cos.ufrj.br, http://lattes.cnpq.br/5823633366826434. Orcid: https://orcid.org/0000-0002-6992-6122

***** Graduanda em Engenharia de Computação e Informação pela Universidade Federal do Rio de Janeiro. nayara.gomes13@ poli.ufrj.br, http://lattes.cnpq.br/1561685344092800. Orcid: https://orcid.org/0000-0003-33480461
} 
methodologies allow our students to be closely guided by tutors, while joining in a collective discussion for an hour each class where critical thinking is exercised in a informatics and society class that discusses the history and contemporary implications of computing. This course also offers a dedicated classroom for women, with an all female staff, as a means to incentivise female participation in the technology area. Many of our students improve their grades and succeed in university entry exams, eventually becoming undergrad voluntary collaborators in new editions of the course. This is a meaningful example of the integration of research, teaching and academic outreach, joining together post grad research produced by the Computer and Systems Engineering program of UFRJ, software development and education in a interdisciplinary course.

Keywords: Informatics. Society. Programming.

\section{Introdução}

O curso é de responsabilidade do Laboratório de Informática para Educação (LIpE), laboratório de extensão localizado no Centro de Tecnologia da UFRJ, o qual se encontra na Cidade Universitária, no Rio de Janeiro. A existência de um curso de ensino de programação gratuito à comunidade não é uma certeza decorrente da existência de uma universidade, e para que essa iniciativa seja compreendida, é necessário conhecer a história do LIpE, esse laboratório fundado em 1994 com o objetivo de apoiar o ensino, pesquisa e extensão na área de informática e educação.

Com uma proposta de ensino através da prática, o LIpE exerceu seu viés extensionista desde a sua fundação. Atuando pela primeira vez através da participação no projeto Minerva, que visava qualificar professores de escolas públicas, o LIpE dava continuidade a projetos em comunidades que vinham sendo realizados desde 1992. Para equipar os laboratórios das escolas envolvidas no projeto, como o Centro Integrado de Educação Pública (CIEP) Gustavo Capanema, o LIpE contou com doações, que muitas vezes eram de máquinas velhas que necessitavam de reformas, o que propiciou a formação de uma equipe com o domínio da reciclagem do lixo eletrônico.

É essa competência de reconstrução de computadores que levou o LIpE a atuar, em 2017, no CIEP Brigadeiro Sérgio Carvalho, em Campo Grande, reciclando máquinas antigas doadas para equipar um laboratório de informática na unidade escolar. Para que o esforço fosse devidamente aproveitado, era necessário construir as condições para que o laboratório fosse utilizado e mantido pelos estudantes e funcionários locais, uma capacitação de multiplicadores. Portanto, o LIpE inaugura um curso de introdução à programação na linguagem Python para os estudantes do ensino médio do CIEP. As aulas ensinavam os preceitos básicos da programação, como funções, listas e estruturas condicionais, concluindo-se o curso com um projeto prático no qual seriam aplicados os conhecimentos obtidos. Uma parte dos concluintes do curso eram convidados a atuar como monitores, acompanhando novos estudantes nas turmas seguintes e ajudando a operar o laboratório em outros dias e horários na escola.

Esse modelo, inaugurado nas escolas públicas, inspirou a criação de um curso mais complexo e estruturado na própria universidade, buscando reunir estudantes de diversas escolas públicas do Rio de Janeiro que se encontrariam e aprenderiam programação enquanto descobririam o ambiente universitário e seus integrantes. Em seu novo modelo, as aulas foram deslocadas para o fim de semana de forma a não atrapalhar as outras atividades escolares, sendo ministradas aos sábados. 


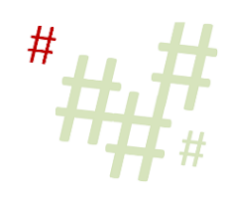

Figura 1 - Turma de programação de 2019

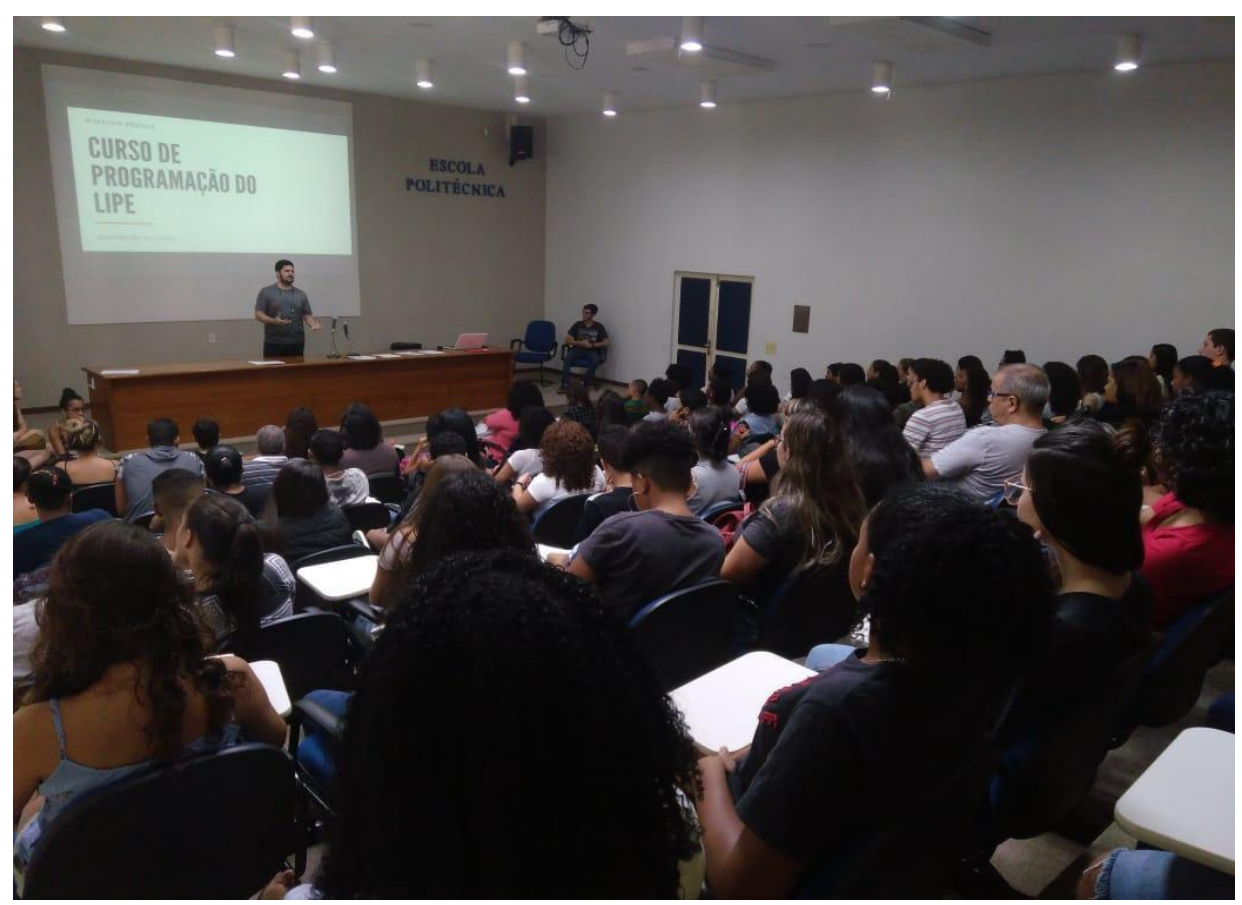

Fonte: Os autores (2019).

O curso também é destinado para alunos de escola pública e busca propagar e popularizar o ensino de programação, o que implica em turmas de grande diversidade, como pode ser observado na Figura 1. As aulas são estruturadas para que os alunos pratiquem os exercícios propostos enquanto são auxiliados por um grande número de monitores (cerca de um monitor para cada dois alunos), o que possibilita uma aproximação real de cada monitor com uma dupla específica ao longo das atividades. Com início às $8 \mathrm{~h}$ e término às $12 \mathrm{~h}$, as atividades eram divididas em três horas destinadas ao ensino da lógica de programação e uma hora de aulas contextuais de Informática e Sociedade, sendo esta lecionada por um doutorando do Programa de Engenharia de Sistemas e Computação (PESC) e integrante do LabIS.

O curso é construído através de uma pedagogia de projetos (PAPERT, 1980), que incentiva a produção de artefatos gradualmente mais complexos pelos estudantes, que por sua vez incorporam os conteúdos aprendidos enquanto inserem aspectos e temáticas alinhadas aos seus interesses e vivências pessoais. Seymour Papert (1980) acreditava que os computadores tinham um potencial pedagógico mais amplo do que a mera substituição dos cadernos e transparências, a implementação de computadores poderia alterar a lógica de funcionamento dos atores presentes em sala de aula, colocando os estudantes no papel ativo de educadores ao serem confrontadas com a possibilidade de ensinar as máquinas e produzir resultados tangíveis (códigos e programas) durante o processo. Desta forma, os estudantes do curso são desafiados pelos monitores a produzir transformações em seus projetos, aprimorando e reinventando o que imaginavam ser possível. Ao final do curso, os projetos finais são apresentados para todas as turmas em um auditório e são abertos para sugestões e críticas dos demais professores, monitores e alunos do curso.

\section{0 que ensinar para futuros profissionais da área de tecnologia?}


O convite para inclusão de aulas de Informática e Sociedade, no curso de programação, surgiu de um graduando com experiência profissional que partia da percepção de que a formação universitária oferecia pouco contexto para os conhecimentos lecionados. A proposta desse graduando era construir mais do que as competências ferramentais, mas a capacidade de pensar criticamente na resolução dos problemas computacionais.

A participação do LabIS em um curso de programação é pensada a partir do questionamento sobre as possíveis contribuições que a linha de pesquisa Informática e Sociedade poderia oferecer para alunos do ensino médio: "Existiria relevância em ensinar conteúdos da pós-graduação para estudantes tão jovens?". A partir das pesquisas desenvolvidas pelo LabIS, procurei relacionar os temas abordados aos desafios presentes nas relações entre computadores e sociedade que possam surgir na atuação do programador.

A premissa inicial para a construção da grade de conteúdos a serem propostos é a necessidade de situar, de alguma forma, os conhecimentos nas vidas dos estudantes, produzir o curso com eles e não para ou sobre eles. A contribuição desejada das aulas seria construir com o estudante um olhar sociotécnico, ou seja, uma indissociabilidade do social e do técnico e a não-neutralidade da tecnologia.

As referências selecionadas abrangem uma análise sociotécnica das tecnologias da informação e comunicação contemporâneas, além de discussões de caráter mais histórico. A disciplina procura trazer para o estudante referências locais do debate de tópicos, como o questionamento da neutralidade científica, a tecnofilia, a linearidade do progresso científico e o questionamento do modelo de difusão tecnológica. O curso conta com cerca de treze aulas, sendo uma de apresentação e uma de encerramento, existindo, portanto, onze temas abordados durante seu o desenvolvimento.

O curso é iniciado com um questionamento amigável do assumido como óbvio; a aula “O que é um computador?" (LEVY, 1999; WINER, 1948) é elaborada com a intenção de desconstruir uma narrativa linear e única da história dos computadores, problematizando os grandes gênios e o progresso inequívoco desses artefatos. Nessa aula, os estudantes aprendem como a matemática e a programação são linguagens que possibilitam a operação dos computadores, também debatemos a presença feminina na computação historicamente.

O segundo tema abordado continua com a jornada pela narrativa histórica da computação, focando no papel dos computadores na guerra através da obra The closed world (EDWARDS, 1995) para situar os interesses políticos envolvidos na construção da orientação desses artefatos. Além de uma abordagem histórica, essa aula problematiza a tecnofilia utilizando-se das distopias produzidas pela cultura pop em um debate sobre automatização de armas e da ilusão do controle criado pelos computadores.

"O cidadão codificado" (FEITOSA, 2010) é baseado na obra homônima do doutorando do LabIS e dá o tom para o tema de bancos de dados de interesse público. Essa aula discute a construção de categorias e o transbordamento consequente desse ato. Ela é uma crítica filosófica da neutralidade a partir do quotidiano e das definições abrangentes que atuam em nossa realidade percebida, por exemplo, o enquadramento das categorias de pobreza utilizadas pelo programa Bolsa Família.

Contracultura, Hackers e Movimento Maker (JACKSON, 2014, 2016; ROSZAK, 1988), inspira-se na cultura brasileira da gambiarra, do reparo improvisado e dos grandes mercados de eletrônicos das periferias para explicar a história das empresas de garagem e da revolução cultural que fundamentou o salto da computação do mercado empresarial para a esfera pessoal. Abordamos também as redes de manutenção e infraestrutura que permitem o 
funcionamento das tecnologias e os esforços necessários de adaptação para implementação de redes em novos territórios.

Computadores, pós-colonialismo, gênero e raça (CHUN, 2009; 2011; MEDINA, MARQUES, HOLMES, 2014; SAID, 1978), se debruça sobre a tecnologia, repensando sua definição de forma mais abrangente. Relacionamos a assimetria colonial entre metrópoles centrais e periferias com a assimetria de gênero e raça da narrativa científica. Exploramos a importância de pensar quem são os criadores das tecnologias e os vieses e crenças que são reproduzidos em sua fabricação.

Computador do ou no Brasil? (MARQUES, 2003; SILVA, 2012; BENEDICT, 2006), debate a relação entre tecnologia e independência utilizando-se das diversas histórias nacionais construídas ao redor da reserva de mercado para computadores estabelecida no Brasil. Além de pensar os interesses nacionais, nesta aula o domínio da tecnologia é situado para os estudantes em sua integração com a indústria e o mercado de trabalho.

Moedas, criptomoedas e moedas sociais (DAVIES, 2002; FARIA, 2018; SCHAR, 2018), é uma breve viagem ao mundo dos mercados, trocas e moedas que estabelece a relação entre registros confiáveis e monetização. A tecnologia de Blockchain e as várias moedas digitais são explicadas e relacionadas com o mundo informacional que as sustentam. Situamos a discussão no contexto social brasileiro através da apresentação dos bancos sociais que atuam nas periferias do país.

Deepweb, a internet e o ciberespaço (EDWARDS, 1995; CHUN, 2006, 2011), narra a história da internet e explica sua materialidade e modo de funcionamento. Abordamos o surgimento da web 2.0 e da percepção de interatividade através da concepção de inspiração literária de ciberespaço. Conceitos como privacidade, anonimato e militância são problematizados através de exemplos da literatura e da história brasileira recente.

Moralidade Computacional (LESSIG, 2006; LATOUR, 2012; LEE, 2017), é uma aula que situa o debate sobre ética e moral em termos da Teoria Ator-Rede (TAR), de forma a instruir o profissional da tecnologia sobre os efeitos das suas ações e das capacidades oferecidas pelos artefatos que cria. Situamos a discussão em dilemas éticos da automatização, com exemplos de veículos, armas e outras tecnologias.

Informática na Educação (FOUCAULT, 1987; FREIRE, 1987; PAQUETE, 2009; PAPERT, 1980; SEVERO, 2016), explora a história da educação e sua gradual institucionalização. O tema da utilização de novas tecnologias em sala de aula é colocado em contraste com a forma de apropriação e a função dada aos computadores na educação. Localizamos a discussão da inovação e da criatividade no campo pedagógico e exploramos as formas como a tecnologia pode aprimorar a imaginação e o engajamento dos estudantes no processo de aprendizagem.

Redes sociais, manadas e liberdade de expressão (MALINI; ANTOUN, 2013; SOBRAL, 2016; SOUSA, 2013; WHALEN, 2011), aborda algumas das principais teorias da comunicação, comparando o cenário das mídias tradicionais com as redes sociais contemporâneas. Abordamos o problema das notícias falsas em contraste com a recente multiplicação e descentralização de narrativas, observando o efeito dos algoritmos e do design profissional no nosso consumo de informações. Exploramos também a literatura através de comparações entre distopias e cenários atuais de violência e intolerância fomentados em grupos nas redes sociais.

A escolha dos temas e autores de referência, muitos dos quais celebrados na área dos estudos de Ciência, Tecnologia e Sociedade (CTS), obedecem a duas motivações: a utilização 
das referências aplicadas nas pesquisas, dissertações e teses produzidas pelos integrantes da linha de pesquisa em Informática e Sociedade do PESC e as referências utilizadas na disciplina Computador e Sociedade, oferecida para os alunos de graduação em Engenharia de Computação e Informação da UFRJ. O leitor mais atento pode perceber que o tema gênero ou a mulher na computação, aparece somente no título da aula "Computadores, pós-colonialismo, gênero e raça". No entanto, aulas específicas do tema "gênero" estão em desenvolvimento.

As aulas contextuais passaram por experimentações ao longo dos anos de existência do curso, tendo assumido três diferentes propostas. Inicialmente as aulas eram palestras, monólogos direcionados pelo professor, que explicava o conteúdo teórico com auxílio de slides. O segundo formato contava com filmes curtos de cinco minutos sobre um tópico, que era seguido de dez minutos de escrita reativa sobre o tema a ser debatido no restante da aula. $\mathrm{O}$ formato mais recente é um debate através de perguntas contidas nos slides, apresentando em cada página um questionamento que busca inquietar os estudantes e provocar reações que possibilitem a construção do tema. A substituição do modelo inicial por uma abordagem mais interativa centrada em vídeos foi motivada pela percepção de que os estudantes assistiam às aulas passivamente, pouco contribuindo com questionamentos.

A dificuldade de acessar o aprendizado dos estudantes sem a aplicação de uma avaliação (modelo pedagógico também rejeitado por nós devido as suas limitações como termômetro do aprendizado), quando somada a necessidade do professor de aprimoramento do material didático para as próximas edições do curso, nos levaram a prosseguir com a experimentação. $\mathrm{O}$ segundo formato centrado em vídeos e escrita também apresentou problemas, pois os estudantes meramente replicavam as opiniões e as percepções apresentadas quando não possuíam qualquer outro embasamento ou questionamento. A adoção de um "caminho do meio" com o retorno dos slides, mas somados a perguntas e debates direcionados buscaram produzir uma maior interatividade entre estudantes e professor. O objetivo é construir uma pedagogia centrada na pergunta (FREIRE, 1987), em que as respostas são reconhecidas em suas limitações e retiradas da centralidade narrativa linear que pressupõe as aulas tradicionais.

Os monitores envolvidos nos cursos também se beneficiam das aulas contextuais, que possuem conteúdos que muitas vezes não estão presentes na graduação da universidade. A participação dos monitores por meio de perguntas e contribuições baseadas em suas experiências e conhecimentos produzem resultados ainda melhores para a turma, intensificando os questionamentos e reflexões provocadas nos estudantes. Os voluntários que se envolvem com o curso são recompensados com horas de extensão, as quais são exigidas pela universidade para sua formação. No entanto, em algumas situações (quando há engajamento continuado, recursos e vagas), os monitores podem acabar integrando a pequena equipe de bolsistas do LIpE e do LabIS, transformando suas experiências no curso de programação em material de pesquisa e temas para apresentação de trabalhos e artigos em eventos.

\section{Monitora é educadora? Um relato de experiência e um olhar sobre a turma exclusiva para Meninas.}

Uma percepção inescapável aos olhos daqueles que ingressam em uma sala de aula cujo tema é programação, computação ou até mesmo tecnologia, é a presença majoritária de estudantes do sexo masculino, sendo raro encontrar mulheres nessas áreas até mesmo como educadoras. Curiosamente, essa predominância masculina não se verifica historicamente, pois durante a construção do primeiro computador brasileiro, a professora Edith Ranzini da Universidade de São Paulo foi uma das doze mulheres envolvidas em sua construção. No entanto, as salas de cursos de tecnologia hoje, inclusive com as nossas iniciativas de ensino, 
apresentam públicos majoritariamente masculinos.

Em nossa experiência com o ensino de programação em escolas que tiveram seus laboratórios reformados pelo LIpE, como o CIEP Brigadeiro Sérgio Carvalho, percebemos uma presença feminina maior devido ao funcionamento habitual em aulas e atividades da escola. Lá um pequeno grupo de meninas criaram um grupo autointitulado Programadoras Digitais Fantásticas (PDF), que se uniram para, após o curso, fazer um aplicativo que auxiliasse as habitantes do bairro na denúncia de casos de violência contra a mulher. Decidimos, portanto, criar uma turma exclusivamente feminina, como pode ser visto nos cartazes de divulgação da Figura 2, para possibilitar isso era necessário também uma equipe exclusivamente de tutoras e professoras. Como estávamos cientes da existência de coletivos de mulheres programadoras, buscamos ajuda dos coletivos Minervas Digitais (UFRJ) e Pyladies (UFRJ), que infelizmente mostraram pouco interesse na colaboração com o curso. Em razão dessa grave realidade da mulher na computação, convidamos para escrever a partir deste parágrafo, uma de nossas monitoras que contribuirá com o relato de sua experiência.

Figura 2 - Cartazes de divulgação do curso de programação.

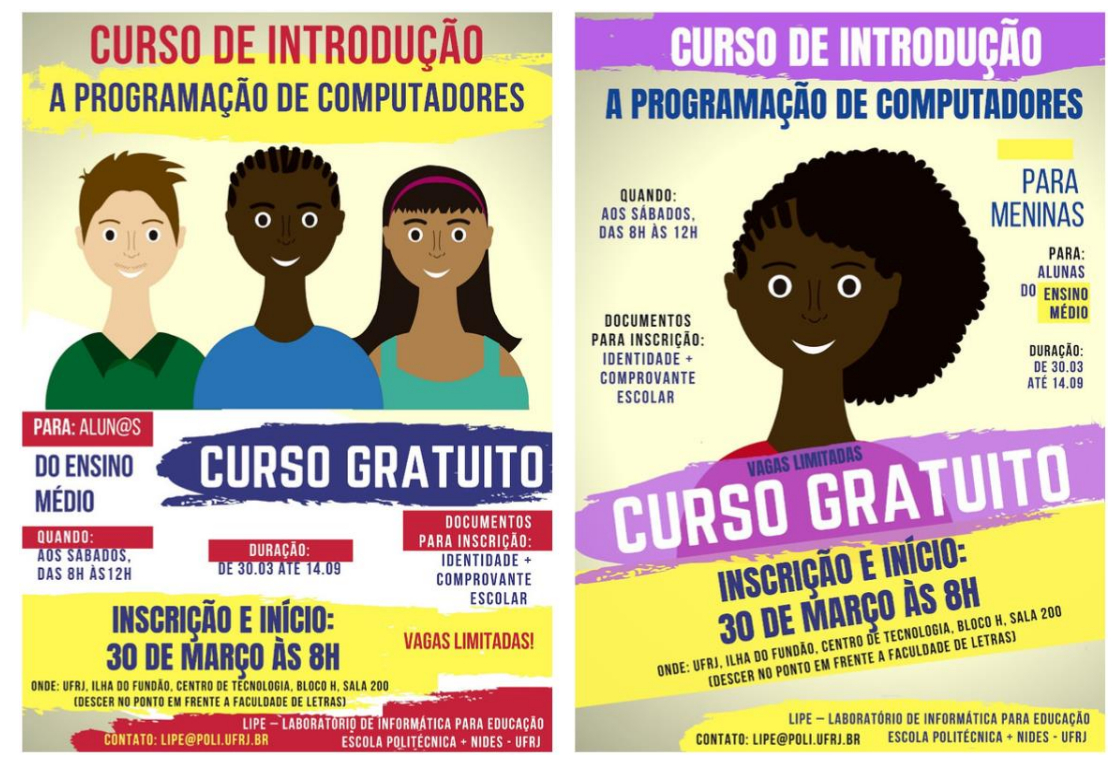

Fonte: Os autores (2019)

Sempre acreditei que, através da educação e conhecimento, poderíamos contribuir para a construção de um mundo melhor e mais humano. Quando passei para a graduação em Engenharia de Computação e Informação da Universidade Federal do Rio de Janeiro (UFRJ), buscava me envolver com algo maior, que transpassasse o Campus e fosse capaz de alcançar lugares mais distantes, podendo ajudar pessoas. Ansiava por compartilhar não somente meu conhecimento através de aulas e tarefas propostas, mas contribuir para a potencialização de mentes, fazendo-as enxergar o que elas têm de melhor. Desejava ser uma multiplicadora, ressaltando a importância de usar e compartilhar o que se sabe para contribuir com a construção de um mundo mais humano e perpetuando tal prática para gerações futuras.

Durante o evento de recepção de calouros do meu curso, alguns dos meus veteranos me apresentaram ao Laboratório de Informática e Sociedade (LabIS), um grupo de pesquisa extensionista focado na contribuição para construção de um Brasil mais justo e igualitário, com projetos de caráter interdisciplinar voltados para a sociedade. Desde então, senti o desejo de fazer parte dessa equipe, mas devido ao conturbado início da graduação, participar de uma 
atividade extra não seria possível. Existe um grande salto de quantidade e complexidade do conteúdo lecionado entre o ensino médio e o superior. Os tópicos abordados nas escolas, principalmente nas públicas, é extremamente defasado em relação ao conteúdo que é apresentado na universidade, portanto eu escolhi focar em simplesmente estudar e não me envolver com mais nada no início da minha vida universitária.

Entretanto, durante o segundo período da minha graduação, uma amiga me convidou para atuar como monitora de um curso de programação em Python. Apesar de não me considerar apta para ensinar programação a alguém, resolvi participar, pois vi nesse convite a possibilidade de ajudar significativamente alguém que não teve as mesmas oportunidades e de aprender muito mais nesta jornada. Faz quase um ano que estou atuando no curso e posso dizer que está sendo uma experiência incrível e extremamente gratificante.

A presença feminina na computação já foi mais expressiva, existindo não só figuras históricas relevantes em seu desenvolvimento como também uma predominância relacionada às origens da computação em funções de secretariado e ensino de matemática, áreas tradicionalmente marcadas pela presença das mulheres. Nomes, como Ada Lovelace e Grace Hopper despontam como pioneiras na computação, a primeira contribuindo para a concepção e a segunda com a consolidação da máquina. Contudo, desde o surgimento dos computadores pessoais, as mulheres foram desaparecendo da área. Esse desaparecimento é possivelmente relacionado aos estereótipos originados de uma cultura sexista e androcêntrica, em que todo foco de divulgação do computador estava voltado para o público masculino. Ademais, o baixo interesse das meninas pela informática é provavelmente também um resultado da falta de incentivo dado durante a escola para seguir a carreira das ciências exatas e tecnologia.

Apresentamos o mundo da programação para as meninas buscando tornar o conteúdo mais interessante através da apresentação de jogos e programas presentes no cotidiano que podem ser feitos utilizando Python. O conteúdo desenvolvido em cada aula é disponibilizado em uma página da internet improvisada feita para o curso, de forma que as estudantes possam ir para o curso com algum conteúdo teórico desenvolvido. O curso é composto por aulas práticas com, no máximo, duas alunas por máquina, a fim de que, em sala, elas façam a lista de exercícios. Buscamos respeitar a curva de aprendizado individual de cada estudante, sempre oferecendo o auxílio das mediadoras, que dão suporte e acompanham o aprendizado de todo o conteúdo da aula de forma personalizada. Podemos perceber a importância de uma turma exclusivamente feminina no depoimento da aluna Raphaela Mercês:

\begin{abstract}
$\mathrm{Eu}$ sempre tive certo receio de programação, felizmente acabei encontrando muito apoio durante o projeto e pude deixar as inseguranças de lado. [...] Fico muito confortável com o fato de termos uma turma feminina, já que normalmente me sinto bem incomodada e intimidada por homens, então me deparando somente com mulheres, fez com que eu me soltasse mais e pudesse ter uma socialização mil vezes melhor. [...] O curso é meu ponto alto da semana, já que vejo todos que eu gosto, aprendo e faço meu sábado render bem mais, e é satisfatório no fim do dia ver o quanto aprendi e um total alívio em ver o programa rodando. Eu realmente amei ter a oportunidade de fazer parte de uma turma tão incrível. (informação verbal ${ }^{1}$ ).
\end{abstract}

Cada menina pode contar com o apoio das outras que se dispõem a cooperar e ajudar suas companheiras de classe. Para estreitar o vínculo entre elas, promovemos atividades de integração, como cafés da manhã e jogos de grupo. Apesar de nós, monitoras, estarmos em sala para servir as meninas, eu tenho aprendido muito com cada uma das alunas, que compartilham suas experiências de vida e me percebem não como monitora, mas como uma amiga disposta a

\footnotetext{
${ }^{1}$ Entrevista com a estudante Mercês realizada em 2019 durante as aulas do curso.
} 
ajudar, dentro e fora do ambiente escolar. Esse método de ensino que adotamos busca quebrar a hierarquia e o sistema competitivo meritocrático tão enraizado no padrão de ensino brasileiro, criar autonomia, hábito de estudo e aumentar o número de meninas na área da computação.

Figura 3 - Turma exclusivamente feminina de 2019.

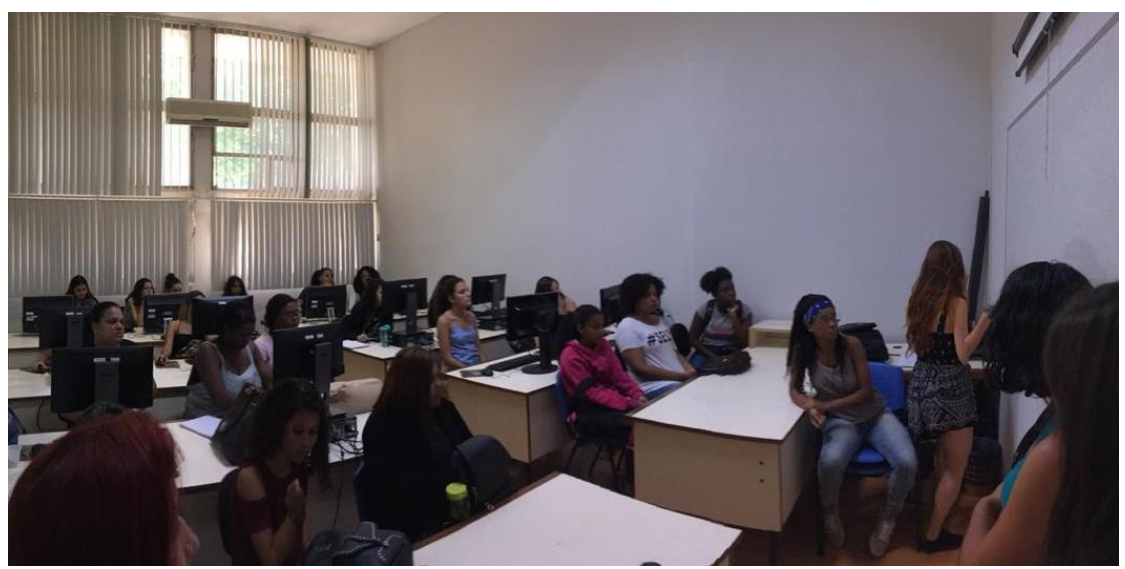

Fonte: Os autores (2019)

Uma outra questão que tenho observado é a desigualdade social presente na turma, como pode ser observado na Figura 3. Por ser um curso gratuito e aberto ao público, e mesmo com a restrição de ser destinado para alunos de escola pública, vemos o quanto a realidade de cada uma é diferente. Ao mesmo tempo que vemos alunas de renda média alta, que têm computador em casa e vêm de escolas públicas nacionalmente reconhecidas, também vemos alunas residentes de áreas periféricas, as quais não têm acesso a um computador e que, muitas vezes, são impossibilitadas de ir para o curso por questões financeiras como, por exemplo, o custo do transporte até a Cidade Universitária. Tentamos constantemente diminuir essa desigualdade, dando um pouco mais de atenção às alunas com maior dificuldade de aprendizado, na tentativa de oferecer oportunidades equivalentes para todas, independentemente de seu desenvolvimento. E tem sido muito bom ver que, através de nosso trabalho, muitas meninas que chegaram minimamente sabendo mexer no computador, estão desenvolvendo rapidamente e nos surpreendendo.

Além das aulas práticas de programação, temos a aula de "Informática e Sociedade", que visa promover uma discussão a fim de contextualizar o aprendizado, relacionando a computação com diversas questões sociais relevantes, como ética, política, autonomia, vigilância, raça e gênero, buscando saber que esses problemas existem e procurando entendêlos. Na turma exclusivamente feminina, essa aula é lecionada por uma mestranda do Núcleo Interdisciplinar para o Desenvolvimento Social (NIDES). Sua presença como professora de "Informática e Sociedade" é significativa para as meninas, pois reforça a representatividade feminina existente na turma, fazendo com que se sintam mais à vontade para exporem suas ideias e opiniões. Em sua aula, as questões abordadas são direcionadas por uma perspectiva feminina, construindo um contexto da inserção da mulher na computação de maneira mais situada e embasada em experiências próprias.

Essa aula tem caráter participativo e aborda questões bem interessantes, não somente para as alunas, que aparentam estar empolgadas e interessadas, mas também para as monitoras, as quais absorvem muitas informações importantes que nem sempre são discutidas na graduação. Essas discussões semanais vêm despertando o senso crítico e a capacidade de reflexão de cada uma, fazendo com que as alunas compartilhem seus pensamentos e opiniões e construam novas perspectivas através desse debate. Particularmente, essa é uma das partes que 
mais tem acrescentado na minha vida pessoal e acadêmica. Durante toda graduação, no curso de Engenharia de Computação e Informação, uma única disciplina possui uma abordagem baseada na interação entre ensino, pesquisa e extensão.Trata-se da disciplina "Computadores e Sociedade", ministrada por membros do LabIS, que utiliza projetos e discussões pautadas na busca por soluções e melhorias na vida comunitária para promover vínculos entre graduandos, pós-graduandos e os que estão "do lado de fora" do mundo acadêmico. Devido à extrema carência de disciplinas que sigam essa linha de estudo interdisciplinar na grade curricular do meu curso de graduação, as discussões que eu presencio nas aulas de "Informática e Sociedade" me proporcionam um contato com pessoas que vivenciam realidades distintas. As diferentes contribuições trazidas por especialistas de áreas interdisciplinares oferecem um tipo de conhecimento singular, apresentado através do debate e propiciando uma renovação na perspectiva e pensamento das alunas.

A experiência que tenho no Curso de Programação para Meninas é singular, pois me concede aprendizados que eu não teria em outro lugar e me dá a oportunidade de conhecer e conviver com pessoas incríveis. Apesar de ser um trabalho voluntário, sou recompensada através de novas amizades, sorrisos e da descoberta do brilho no olhar de alguém que foi apresentado a um mundo novo, onde existe a possibilidade de crescimento, aprendizado e um futuro promissor.

\section{Os desafios da formação de programadores para além dos cursos de graduação}

O objetivo inicial de oferecer uma formação básica em programação para estudantes do ensino médio foi consolidada gradualmente através de cada edição do curso. As turmas iniciais contavam com um público mais próximo da universidade (graduandos e pós-graduandos) que apareceram desejando participar, ocupando as vagas ociosas devido a problemas no alcance e formato de divulgação (exclusivamente no Facebook na primeira edição). Os problemas foram corrigidos através da melhoria dos cartazes, que passaram a possuir maiores especificações e incentivar um maior público feminino, e transferimos a divulgação do curso para apresentações por representantes em escolas públicas e cursos pré-vestibulares sociais de comunidades próximas ao centro universitário.

Enfrentamos problemas constantes referentes a escassez de recursos financeiros para incentivar monitores e estudantes em seu deslocamento aos sábados para o Campus universitário. Desistências de monitores do curso são comuns devido à concorrência com bolsas de outros laboratórios e estudantes deixam de frequentar por falta de recursos, baixo desempenho percebido e competição de tempo entre o trabalho e vida pessoal. 
Gráfico 1 - Número de envolvidos em cada edição realizadas.

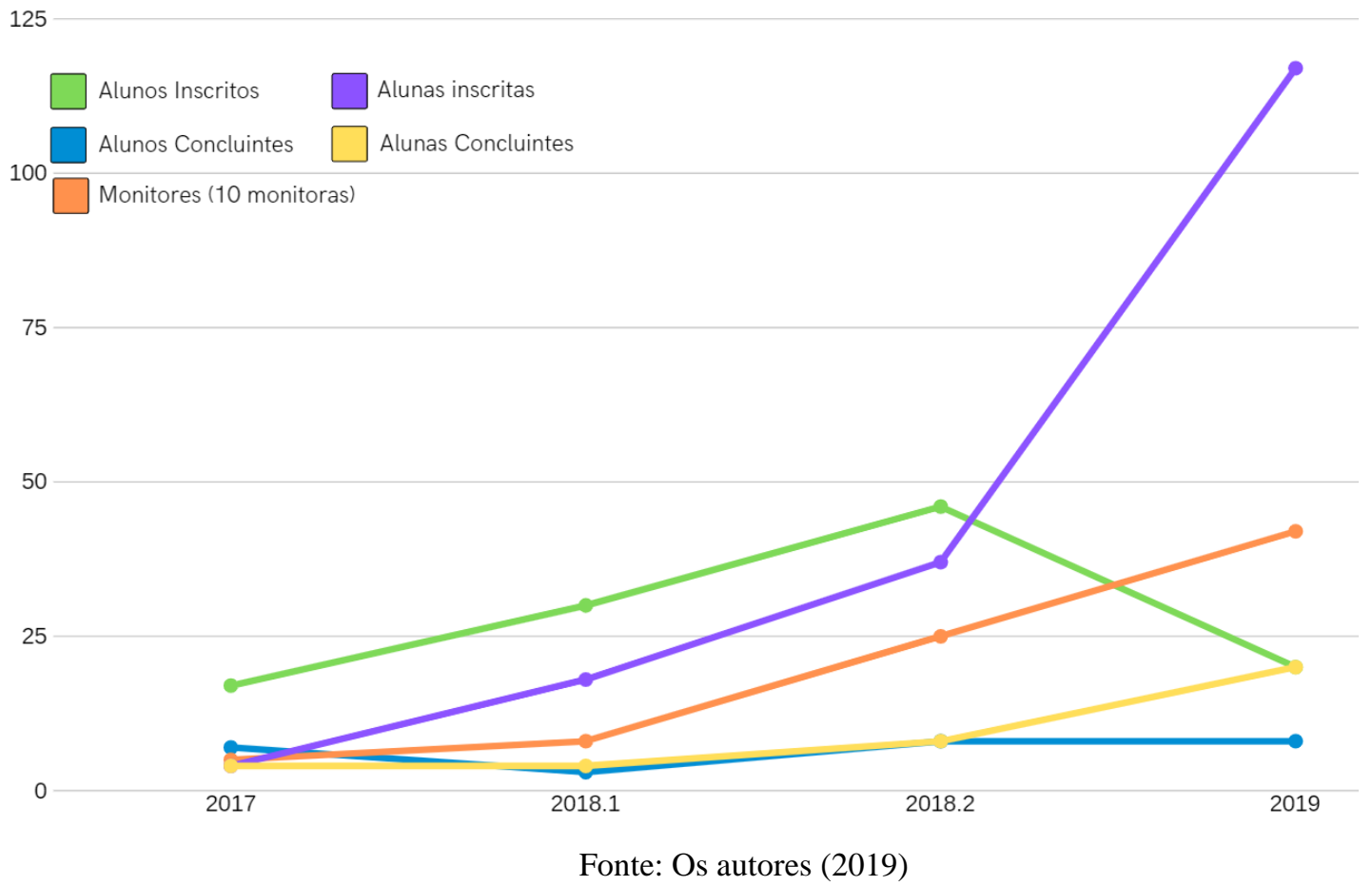

A despeito das dificuldades enfrentadas, como pode ser visto no Gráfico 1, o curso segue expandindo-se (agora com presença feminina predominante) e ocupando diversos laboratórios do Campus (atualmente contamos com três turmas). Uma boa parte dos problemas citados são resultantes do excessivo voluntarismo que caracteriza sua organização, uma vez que não possuímos funcionários ou estudantes exclusivamente dedicados e remunerados em reconhecimento a essa atividade. No entanto, os sucessos do curso apresentam grande relevância, existindo atualmente quatro ex-estudantes de escola pública que frequentaram o curso e que conseguiram ingressar na universidade. Atualmente, os quatro são monitores voluntários que atuam como multiplicadores da experiência enriquecedora que receberam.

Um dos nossos estudantes, que atualmente é monitor, usou seus conhecimentos adquiridos no curso para produzir um software de gestão escolar para a escola pública, onde se formou, com o intuito de facilitar a produção de históricos escolares. Esse curso também tem contribuído direta e indiretamente com a pesquisa de doutoramento de quatro integrantes do LabIS, fornecendo dados, materiais e campo para sua atuação. O curso de programação configura-se, portanto, em um espaço privilegiado para a integração do tripé ensino, extensão e pesquisa.

\section{Referências}

BENEDICT, Anderson. Imagined Communities. 2. ed. Verso, London 2006.

CHUN, Wendy. Control and Freedom. MIT Press, 2006.

CHUN, Wendy. Programed Visions. MIT Press, 2011.

CHUN, Wendy. Camera Obscura. MIT Press, 2009.

DAVIES, Glyn. A history of Money. University of Wales, 2002. 
EDWARDS, Paul N. The Closed World: Computers and the Politics of Discourse in Cold War America. MIT PRESS, 1995.

FARIA, Luiz Arthur. Digitalizações e Moedas Sociais no Brasil e suas (pré) histórias: tensões e mediações com Estados, mercados e tecnologias. Orientador: Henrique Cukierman. Tese de doutorado (Engenharia de Sistemas e Computação). PESC, COPPE, UFRJ, 2018. Disponível em: https://is.cos.ufrj.br/wp-content/uploads/2019/02/LuizArthurSilvaDeFaria.pdf. Acesso em: 16 out. 2019.

FEITOSA, Paulo. O Cidadão Codificado: A digitalização da cidadania em bancos de dados de interesse público. Orientador: Henrique Cukierman. Dissertação de mestrado (Engenharia de Sistemas e Computação). PESC, COPPE, UFRJ, 2010. Disponível em:

https://www.cos.ufrj.br/index.php/pt-BR/publicacoes-pesquisa/details/15/2163. Acesso em: 16 out. 2019.

FOUCAULT, Michel. Vigiar e Punir. nascimento da prisão; tradução de Raquel Ramalhete. Petrópolis, Vozes, 1987.

FREIRE, Paulo. Pedagogia do Oprimido. 17ª ed. Rio de Janeiro, Paz e Terra. 1987.

JACKSON, Steven J. Rethinking Repair. Em: Media Technologies: Essays on Communication, Materiality and Society. MIT Press, 2014.

LATOUR, Bruno. Reagregando o Social: uma introdução à teoria ator rede. Edufba, 2012.

LEE, Chasel. Grabbing the wheel early: moving forward on cybersecurity and privacy protection for driveless cars. University of California, Berkeley, 2017.

LEVY, Pierre. A invenção do computador. In: Cibercultura. Editora 34, 1999.

LESSIG, Lawrence. Code and other laws of cyberspace 2.0, 2006. Disponível em: http://codev2.cc. Acesso em: 16 out. 2019.

MALINI, Fábio; ANTOUN, Henrique. A internet e a rua: ciberativismo e mobilização nas redes sociais. Porto Alegre: Sulina, 2013.

MARQUES, Ivan da Costa. Reserva de Mercado: Um mal entendido caso políticotecnológico de "sucesso" democrático e "fracasso" autoritário. História, Ciências, Saúde Manguinhos, vol. 10(2): 657-81, maio-ago. 2003.

MEDINA, Eden. MARQUES, Ivan da Costa. HOLMES, Cristina. Beyond Imported Magic. MIT Press, 2014.

SAID, Edward. Orientalismo. Phanteon Books, 1978.

SCHAR, Fabian. BERENTSEN, Aleksander. A short introduction to the world of cryptocurrencies. Federal Reserve Bank of Saint Louis, 2018.

SILVA, Márcia Regina Barros da. Para que fazer história da informática? SHIALC, 2012. Disponível em:

https://www.cos.ufrj.br/shialc/2012/content/docs/shialc_2/clei2012_submission_322.pdf

Acesso em: 16 out. 2019.

PAPERT, Seymour. Mindstorms: children, computers, and powerful ideas. Basic Books, 
New York, 1980. Disponível em: http://worrydream.com/refs/Papert\%20\%20Mindstorms\%201st\%20ed.pdf. Acesso em: 16 out. 2019.

PAQUETE, Gilles. Quantophrenia. University of Ottawa, 2009.

ROSZAK, Theodore. O computador e a contracultura. Em: O culto da informação, O folclore dos computadores e a verdadeira arte de pensar. Ed. Brasiliense, 1988.

SEVERO, Fernando. TICs e TACs: o refazimento de softwares e engenheiros no limiar entre as ciências e os segredos. Orientador: Henrique Cukierman. Dissertação de mestrado (Engenharia de Sistemas e Computação). PESC/COPPE, 2016. Disponível em: https://www.cos.ufrj.br/index.php/pt-BR/publicacoes-pesquisa/details/15/2634. Acesso em: 16 out. 2019.

SOBRAL, André. Ações Coletivas em Rede: Um Estudo de Caso Sobre o Anonymous Rio. Orientador: Henrique Cukierman. Dissertação de mestrado (Engenharia de Sistemas e Computação). PESC, COPPE, UFRJ, 2016. Disponível em:

https://www.cos.ufrj.br/index.php/pt-BR/publicacoes-pesquisa/details/15/2692. Acesso em: 16 out. 2019.

SOUSA, Cidoval Morias de. Jornadas de Junho: repercussões e leituras. Campina Grande: EDUPB, 2013. Disponível em: http://editora.ifpb.edu.br/index.php/uepb/catalog/book/160. Acesso em: 16 out. 2019.

WHALEN, John. Persuasive Design: Putting it to use. In: Bulletin of the American Society for Information Science and Technology, 2011. Disponível em: https://asistdl.onlinelibrary.wiley.com/doi/full/10.1002/bult.2011.1720370607. Acesso em: 16 out. 2019.

WINER, Norbert. Cibernética. Scientific American,1948.

Recebido em agosto de 2019.

Aprovado em outubro de 2019. 